\title{
Cancer drugs should add months, not weeks, say experts
}

In the last decade, the world's drug regulatory agencies have approved dozens of new anticancer therapies for everything from lung carcinoma to skin melanoma. Some of these new drugs add months to a patient's life. But others may offer only an extra week or two, on average, often with considerable toxicity and at a cost of thousands of dollars.

Now experts are questioning whether these outcomes provide meaningful benefit to people's quality of life and are urging regulatory agencies to toughen the criteria for drug approval. Such a measure would push pharmaceutical companies to modify the design of clinical trials-a move that some drug makers and doctors worry could shrink the drug market.

"The way we develop drugs is fundamentally flawed," says Ian Tannock, a medical oncologist at Princess Margaret Hospital in Toronto. "A trial should be based on difference in outcome-preferably survival—that would be regarded as worthwhile by a clinician."

Tannock, together with oncologist Alberto Ocana of the Albacete University Hospital in Spain, surveyed a series of randomized phase 3 clinical trials used by the US Food and Drug Administration over the past ten years to approve ten new anticancer therapies.
Although each study showed a statistically significant difference between the control and experimental groups, some of the approved drugs offered only incremental improvements in overall survival or the length of time that tumor progression stayed constant.

For example, the pivotal study behind the 2005 approval of Genentech's Tarceva (erlotinib) for treating pancreatic cancer (when combined with gemcitabine) showed that the tyrosine kinase inhibitor drug increased the median survival by just ten days (J. Clin. Oncol. 25, 1960-1966, 2007). Another study, which led to the 2006 approval of Amgen's Vectibix (panitumumab) for treating advanced colorectal cancer, showed that the drug slowed tumor progression by an average of five days (J. Clin. Oncol. 25, 1658-1664, 2007).

In a commentary published last month, Tannock and Ocana argue that future clinical trials should explicitly specify a three-month increase in median overall survival as the primary endpoint for patients with advanced metastatic solid tumors and four to six months where progression-free survival is the goal (J. Natl. Cancer Inst. doi:10.1093/jnci/djq463, 2010). And the authors call on regulatory agencies to mandate the stricter guidelines.
"As long as these are the rules, you can't expect the companies not to play by them," Tannock says.

Not everyone welcomes the recommendations. Wyndham Wilson, a lymphoma researcher at the National Cancer Institute in Bethesda, Maryland, argues that the proposed clinical endpoints are somewhat arbitrary. "What constitutes a clinically meaningful difference? Six months is obvious, but where do you cut the line?" What's more, he adds, simply focusing on median responses often ignores important outlier effects that could merit approval for an experimental drug. "The difference in overall survival may not be great, but it may be driven by a great benefit to a small group," he says.

Drug developers maintain that adopting rigid endpoints could have negative impacts on cancer drug development by shifting venture capital and other investments to other diseases deemed less risky. Meanwhile, regulatory agencies are wary of setting fixed thresholds. In some situations, says Francesco Pignatti, head of oncology, hematology and diagnostics at the European Medicines Agency in London, "we consider small differences in endpoints to be of sufficient clinical value."

Hannah Hoag

\section{Funds go toward biomedical business incubators in Mexico}

MEXICO CITY_For decades, Mexican biomedical scientists have focused on basic research, looking with suspicion on those few colleagues who spoke of applying discoveries in the clinic or generating profits. However, this attitude is changing, according to Juan Pedro Laclette, general coordinator of the Scientific and Technological Consultative Forum, the main research advisory agency to the Mexican government: "Scientists are showing more interest in innovation and its potential to generate revenues," Laclette says.

In the past two years, a group of high-ranking scientists from the National Autonomous University of Mexico (UNAM), the largest federally funded university in the country, have poured 15 million pesos ( $\$ 1.2$ million) of their own money into getting startups off the ground. "This is unprecedented," says Carlos Arias, director of the UNAM's Biotechnology Institute in Cuernavaca, in the state of Morelos, where most of the entrepreneur-scientists also work. Arias notes that the establishment of a technology transfer office at the institute has contributed to the entrepreneurial environment.

One of the startups supported by the endeavor is a company known as Biodetecta, which officially completed its business incubation period in December-making it the first of these startups to do so. That same month, a subsidiary of Biodetecta called Biohominis, which is devoted to molecular and genetic testing in humans, announced it had secured a partnership with Mexico's National Institute of Genomic Medicine.

"By April 2011, two more subsidiaries dedicated to animal and plant molecular testing will be available," says Eduardo Valencia, chief executive officer of Biodetecta.

Money from the government of Morelos State has helped fund the business incubator program. Additionally, a grant of 6 million pesos from the Institute of Science and Technology of Mexico City and the National Science and Technology Council subsidized some of the cost of operation and helped pay for Biohominis's development of a diagnostic kit for the H1N1 influenza.

The benefits of home-grown biomedical businesses are clear, according to Isabel Tussié-Luna, chief operations officer of Biodetecta: "Because some of our scientific partners are experts on [the] genetic variability of the Mexican population in areas like cancer, diabetes and obesity, we have the unique capability to assess the analysis results in the context of the Mexican population."

Laura Vargas-Parada 